\title{
Politización estudiantil y rol de la toma en las movilizaciones de 2011 en Chile ${ }^{1}$
}

\author{
Juan Fernández Labbé2
}

\author{
"al interior de la toma, fue construir un mundo \\ totalmente nuevo (...) \\ todo lo que nos habían dicho desde que nacimos hasta esa época, \\ eran básicamente mentiras y todo se podía cambiar" \\ (Grupo de Discusión con varones estudiantes secundarios, \\ participantes de tomas en el año 2011).
}

Fecha de recepción: 4 de marzo de 2019

Fecha de aprobación: 4 de mayo de 2019

Fecha de publicación: 30 de julio de 2019

\begin{abstract}
Resumen
El artículo aborda las características y significados del proceso de politización experimentado por estudiantes activistas de base en el marco de las movilizaciones estudiantiles de 2011 en Chile, específicamente en cuanto a sus experiencias como participantes en tomas de establecimientos. Se analiza material cualitativo generado mediante ocho grupos de discusión con estudiantes hombres y mujeres, participantes activos del movimiento pero que no ocupan un cargo de representación estudiantil (dirigencia o vocería), pertenecientes a las principales universidades y liceos emblemáticos. Se observa la apropiación de una política resignificada, proceso al cual contribuyen las tomas, constituidas en espacio de autonomía y aprendizaje, de cuestionamiento del orden cotidiano y de puesta en práctica de reglas y funciones autodefinidas colectivamente. Los estudiantes han perdido el miedo al debate y al reclamo, al cuestionamiento y a la disconformidad, al tiempo que han aprendido a proponer y a trabajar por la construcción de una realidad diferente. La internalización de una visión crítica frente a la realidad y la comprensión de sí mismos como actores relevantes para que los cambios puedan tener lugar, representa un aprendizaje que cimenta una base de acción futura y una conciencia propiamente política.
\end{abstract}

Palabras clave: activismo, movimiento estudiantil, politización

Este trabajo presenta un análisis derivado de una investigación más amplia, enmarcada en el desarrollo de la tesis para optar al grado de Doctor en Sociología. Su realización contó con el apoyo del Programa de Capital Humano Avanzado de CONICYT a través de una Beca para Doctorado en el extranjero 2009-2013.

2 Doctor en Sociología, Universidad Complutense de Madrid. Santiago, Chile. Contacto: juanfernandezy@gmail.com 


\title{
Student politicization and role of the toma in the mobilizations of 2011 in Chile
}

\begin{abstract}
This paper addresses the characteristics and meanings of the process of politicization experienced by grassroots student activists in the framework of the 2011 student movements in Chile, specifically in terms of their experiences as participants in school takeovers (tomas). It analyzes qualitative material generated through eight discussion groups with male and female students from emblematic universities and high schools who are active participants in the movement, but who do not occupy a position of student representation (leader or spokesperson). The study looks at the process of appropriation of a re-signified policy, where tomas constituted in a space of autonomy and learning contribute to the challenging of the daily order and put into practice rules and functions that have been collectively defined by participants. Students have lost their fear of debate and complaint, questioning and discontent, while learning to make proposals and work towards the construction of a different reality. The internalization of a critical approach to reality and the understanding of themselves as relevant actors for making a change represents a learning process that builds the basis for future action and political awareness.
\end{abstract}

Keywords: activism, student movement, politicization

\section{Politização estudantil e o papel da ocupação nas mobilizações de 2011 no Chile}

\begin{abstract}
Resumo
$\mathrm{O}$ artigo aborda as características e significados do processo de politização experimentado por estudantes ativistas de base no marco das mobilizações estudantis de 2011 no Chile, especificamente no que refere a suas experiências como participantes em ocupações de estabelecimentos. Analisa-se material qualitativo gerado através de oito grupos de discussão com estudantes homens e mulheres, participantes ativos do movimento, mas que não ocupam um cargo de representação estudantil (líderes ou porta-vozes), pertencentes às principais universidades e liceus emblemáticos. Observa-se a apropriação de uma política ressignificada, processo no qual contribuem as ocupações, constituídas em espaço de autonomia e aprendizagem, de questionamento da ordem cotidiana e da colocação em prática de regras e funções autodefinidas coletivamente. Os estudantes têm perdido o medo ao debate e ao reclamo, ao questionamento e à desconformidade, ao mesmo tempo em que têm aprendido a propor e a trabalhar pela construção de uma realidade diferente. A internalização de uma visão crítica perante a realidade e a compreensão deles próprios como atores relevantes para que as mudanças possam ter lugar, representa uma aprendizagem que cimenta uma base de ação futura e uma consciência propriamente política.
\end{abstract}

Palavras-chave: ativismo, movimento estudantil, politização. 


\section{Introducción}

El 2011 fue el año de la protesta social, en el mundo y también en Chile $e^{3}$. El contexto global: expansión del neoliberalismo y de la democracia liberal, a la vez que persistencia de desigualdades sociales y desbalance entre los poderosos intereses de una minoría y los del conjunto de los ciudadanos (Held, 1997; Crouch, 2004, 2011; Della Porta, 2012) $)^{4}$. Lo anterior genera desafección política, baja en la participación electoral y descenso en la participación político-partidista, con lo que los grupos de presión cobran fuerza en el juego político y, a la vez, las movilizaciones sociales se extienden, canalizando la expresión de las demandas e intereses de la ciudadanía fuera de las instituciones (Beck, 2002; Resnick, 2007; Mouffe, 2007).

En Chile, el movimiento estudiantil se hacía eco en parte de todo aquello, pero se enraizaba en fenómenos nacionales particulares de las últimas cuatro décadas: privatización y mercantilización de derechos sociales, herencia institucional autoritaria, desafección electoral y desconfianza en las instituciones, desigualdad y segregación social, y expansión de las clases medias, a la vez que sensación de vulnerabilidad, inseguridad y deterioro del vínculo social (Moulian, 1997; PNUD, 1998; López y Figueroa, 2012; OCDE, 2012; Mayol, 2012; Garretón, 2014).

La movilización estudiantil se presentó como una respuesta ante el proceso de mercantilización de la educación ${ }^{5}$, establecien-

\footnotetext{
3 El año 2011 surgieron, entre otros, la denominada Primavera Árabe, el 15-M o Movimiento de los Indignados, Ocuppy Wall Street y el Movimiento Estudiantil en Chile. El 15 de octubre de 2011 se convocó a una protesta a nivel mundial en el marco de la cual se movilizaron 951 ciudades de un total de 82 países, en el marco del denominado "movimiento del 99\%" (Funes, 2012).

4 Los países que celebran elecciones razonablemente libres, condición mínima para ser considerados democráticos, llegaban a 191 en el año 1999 (Crouch, 2004). Después de la crisis financiera internacional de 2008 el neoliberalismo está extendiéndose con más fuerza que nunca, ya que los Estados, como respuesta a la crisis, recortan enérgicamente el gasto público y la inversión en bienestar (Crouch, 2011).

5 Para ver en detalle el despliegue de la educación como un mercado, ver Mönckeberg (2007).
} 
do como demandas fundamentales el fortalecimiento y gratuidad de la educación pública, el fin al lucro en la educación y la democratización de las entidades educativas. Los principales actores fueron los estudiantes universitarios (organizados a través de la Confederación de Estudiantes de Chile, CONFECH) y secundarios (aglutinados en la Asamblea Coordinadora de Estudiantes Secundarios, ACES, y la Coordinadora Nacional de Estudiantes Secundarios, CONES), sumados los docentes (el Colegio de Profesores) y, de forma indirecta, un conjunto de otros colectivos sociales (sindicatos, funcionarios públicos, mineros, etc.). Se habló de un despertar social (Garcés, 2012), de una politización de la sociedad (Mayol, 2012; Muñoz, 2011; Fernández, 2013a) y de una renovación de las fuerzas democratizadoras (Garretón, 2011).

Interesa en este artículo analizar el proceso de politización ocurrido en quienes fueron protagonistas activos del movimiento, pero desde las bases del mismo y no desde sus cúpulas o dirigencias. La distinción no es trivial, por cuanto ha sido estudiado el vínculo entre líderes estudiantiles, partidos políticos y carreras políticas posteriores (Lobos, 2014; Ponce, 2016) ${ }^{6}$, pero se ha explorado menos en los activistas de base, en el marco de un contexto que podríamos definir como poco promotor de la politización (sin educación cívica o ciudadana en el currículo de las escuelas ${ }^{7}$ y un desprestigio y desconfianza en niveles alarmantes de la actividad política institucional ${ }^{8}$ ).

\footnotetext{
$6 \quad$ A la fecha, los dos principales dirigentes universitarios durante las movilizaciones del año 2011 son diputados de la República: Giorgio Jackson (RD) y Camila Vallejo (PC), a los que se suman otros nombres de diputados exdirigentes, como Gabriel Boric (MA). Para aproximaciones a las trayectorias políticas de los dirigentes universitarios chilenos en las últimas tres décadas antes de las movilizaciones estudiantiles de 2006 y 2011, ver el trabajo de Micaela Lobos (2014) y para un estudio posterior a las jornadas de movilización de 2006 y 2011, ver el de Camila Ponce (2016).

7 En 1997 se eliminó la asignatura "Educación cívica" del currículo escolar y se planteó que la formación ciudadana sería abordada de manera transversal en las prácticas docentes. En 2018 se aprobó reponerla como asignatura independiente obligatoria para III y IV medio, con el nombre de "Educación ciudadana".

8 De acuerdo con encuestas longitudinales, en el periodo 2009-2012 la confianza en el gobierno descendió del 38,4\% al 17,7\%; en los Tribunales de Justicia del 20,7\%
} 
Por otro lado, si bien en el marco de las jornadas de movilización estudiantiles el repertorio utilizado fue amplio y diverso, las tomas ${ }^{9}$ tuvieron una presencia significativa, situándose en segundo lugar dentro de las acciones de protesta realizadas (después de las marchas y manifestaciones) (Fernández, 2013b), y representando una dinámica de interacción social entre sus participantes, de especial interés para el estudio de la politización ${ }^{10}$.

La pregunta que guía el presente artículo es ¿qué rol, características y alcance tuvo la participación en las tomas, en el proceso de politización de activistas estudiantiles no dirigentes? El propósito es comprender qué características y significados tiene en concreto el proceso de politización experimentado y qué nociones en torno a lo político cobraron fuerza en la experiencia de los estudiantes activistas de base.

\section{Politización y socialización política en tiempos de crisis}

La politización es la capacidad de producir juicios políticos, a la que se llega tras un proceso de socialización (Ponce, 2016), entendido tradicionalmente desde la sociología como el proce-

al 12\%; en el Congreso Nacional del 14,8\% al 7,8\%; y, como corolario, en los partidos políticos del $8 \%$ al 4,4\% (UDP, 2012).

9 Una toma es una ocupación permanente de un establecimiento por parte de los estudiantes, en la cual se produce una desobediencia civil de las normas y autoridades del mismo, pasando la responsabilidad del recinto a manos de los protagonistas de la ocupación. Las clases y demás actividades formales se paralizan y son los grupos estudiantiles los que desarrollan actividades libres y administran la entrada y salida del recinto. La toma en la mayoría de los casos dura día y noche.

10 El recurso de la toma/ocupación de los centros educativos ha estado presente a lo largo de la trayectoria de los movimientos estudiantiles desde las movilizaciones enmarcadas en el movimiento de Reforma Universitaria de fines de la década de los 60: en junio de 1967 los estudiantes de la Universidad Católica de Valparaíso se toman la Escuela de Arquitectura de dicho centro de estudios, y en agosto ocurre lo propio en la Casa Central de la Universidad Católica en Santiago, en un hecho que pasó a la posteridad gracias al colgamiento de un lienzo en el que se leía "Chileno: El Mercurio Miente", en directa alusión al manejo mediático del principal periódico del país, propiedad de Agustín Edwards, fiel representante de la élite nacional conservadora y protagonista, años más tarde, en la gestación del golpe militar de 1973. 
so en el que los individuos internalizan ideas, valores, creencias y pautas de comportamiento de su entorno sociocultural. En el caso de la socialización política, lo que se adquiere son códigos simbólicos que permiten comprender el entorno sociopolítico, situarse y tomar posición ante él (Greenberg, 2017). En dicho proceso intervienen agentes socializadores, entre los que destacan la familia, los pares, los medios de comunicación y las instituciones educativas (Funes, 2003; Sandoval y Hatibovic, 2010; Quintelier, 2013).

En el estudio de los procesos de socialización política de los jóvenes la familia ocupa un rol preponderante, especialmente cuando existen miembros vinculados a la política formal (Ponce, 2016), aunque también las instituciones educativas (liceos de enseñanza secundaria o universidades) son significativas para el aprendizaje político y la profundización o radicalización de sus posiciones (Ponce, 2013, 2016), tanto por las dinámicas formales -elección de centros de alumnos, prácticas docentes(Treviño et al., 2018) como por los intercambios informales entre estudiantes. Por otro lado, las contraculturas o movimientos culturales relacionados con los estilos musicales y de identificación juvenil (por ejemplo, tribus urbanas) también ejercen un rol en el proceso de socialización política. Ligado a lo anterior, los denominados "espacios libres", entornos de pequeña escala en los cuales se elimina el control directo de los grupos dominantes y se favorece la interacción y formación de redes (grupos culturales, grupos de iglesias, círculos cotidianos, entre otros) suelen contribuir a la generación de habilidades, solidaridades e identidades que preceden o acompañan a los movimientos sociales (Poletta, 1999; Poletta y Kretschmer, 2013), contribuyendo también a la politización.

En las últimas décadas la politización, en la ciudadanía en general y en los jóvenes en especial, tiende a desconectarse de las instituciones formales para desplegarse en los espacios sociales más cotidianos, al alcance de la experiencia concreta de cada cual (Lechner, 1999; Alvarado et al., 2008). En ese contexto, los 
movimientos sociales y sus organizaciones constituyen "espacios de experiencia y aprendizaje" (Pleyers, 2010) que permiten a los activistas experimentar en la práctica alternativas de conducta y formas de subjetividad (por ejemplo, relaciones horizontales, delegación limitada, etc.), las cuales también apuntan a defender la autonomía de la propia experiencia contra los poderes económicos, las instituciones y su colonización de los espacios de la vida social.

La denominada "subpolítica" (Beck, 2002), aquella que está al margen y más allá de las instituciones de representación del sistema político formal, se expande y cobra especial importancia entre los jóvenes. Estudios que abordan la conformación de la subjetividad política en jóvenes identifican un tránsito desde una participación institucionalizada Estadocéntrica a una concepción performativa, desarrollada en escenarios cotidianos (Alvarado et al., 2008). Es así como en los jóvenes opera una ampliación de los sentidos de lo político a partir de sus relaciones y creaciones, la mayoría de las veces al margen de la institucionalidad, con prácticas y sentidos locales (Patiño et al., 2014).

La participación en tomas de establecimientos educativos, en el marco de unas jornadas de movilización históricas, constituye un escenario propicio de referencia para analizar los derroteros y significados de esta politización.

\section{Metodología}

La práctica de investigación utilizada es la del Grupo de Discusión (en adelante GD), que sirve para re-producir un diálogo, para re-crear un discurso y permite dejar hablar al grupo (Gutiérrez, 2008), es decir, generar una instancia para que surja el discurso colectivo en relación a un determinado tema. En el GD ocurre un proceso de reproducción de la unidad social de sentido (Ibañez, 1989), en el cual emerge un discurso colectivo representativo del inconsciente estructural (Alonso, 1998). El objetivo del GD, en tanto práctica de investigación, es "buscar la construcción de 
sentido común que grupos sociales determinados hacen en torno a un ámbito (...) hallar los marcos de interpretación a partir de los cuales los sujetos dan sentido a un conjunto de experiencias" (Martín Criado, 1997, p. 95).

Interesa en este caso recoger el significado que los activistas dan a su participación en las tomas, como a sus visiones sobre la política, eventualmente modificadas a partir de dicha participación. El diseño contempló la realización de ocho grupos con estudiantes secundarios y universitarios, hombres y mujeres, de liceos emblemáticos ${ }^{11}$ y universidades pertenecientes al $\mathrm{CRUCH}^{12}$, cuyas federaciones de estudiantes son miembros del $\mathrm{CONFECH}^{13}$, que participaron activa y regularmente de las movilizaciones, sin ser dirigentes o voceros del movimiento.

Se separaron los grupos por género (masculino/femenino) y por nivel educativo (secundario/universitario). Se definieron cuatro perfiles y la realización de dos GD para cada perfil, buscando heterogeneidad y validez a objeto de lograr representatividad estructural (que da cuenta de la diversidad de discursos), así como saturación (punto en el cual la información nueva no añade nada relevante a lo ya obtenido en los grupos previos, lo cual se logró al hallar en cada réplica de perfil la consistencia de un núcleo discursivo reiterado) ${ }^{14}$.

11 Se denomina "liceos emblemáticos" a los establecimientos educacionales públicos reconocidos por su tradición y prestigio, que suelen obtener los mejores resultados en las pruebas de selección universitaria y adicionalmente han cumplido un rol protagónico en las movilizaciones estudiantiles.

12 Consejo de Rectores de Universidades de Chile. Pertenecen a él las universidades más importantes del país y que han jugado un rol protagónico históricamente en las movilizaciones estudiantiles.

13 La Confederación de Estudiantes de Chile es la organización estudiantil que congrega a las federaciones de estudiantes de las universidades chilenas. Hasta 2011 incluía solo a las denominadas universidades tradicionales o del CRUCH; sin embargo, a partir de ese año se fueron incorporando representantes de universidades privadas no miembros del Consejo de Rectores.

14 En el anexo se presenta un detalle de la conformación de los GD y de las características de los informantes. 
Para la selección de los informantes se tomó como guía los Criterios Maestros del Muestreo Cualitativo (Valles, 1997, 2002). En primer lugar, la competencia narrativa atribuida de los actores, es decir, identificar a quiénes se considera que son competentes para entregar la información buscada; se identificó como perfil a los activistas de base, participantes activos y regulares del movimiento, pero que no ocupan un cargo de representación estudiantil (dirigencia o vocería). La razón de ello fue enfocar la mirada hacia un conjunto más amplio de actores y profundizar en los discursos de quienes no necesariamente habían tenido tribuna, siendo la base del movimiento ${ }^{15}$.

En segundo lugar, actores pertenecientes a las dos esferas estudiantiles movilizadas: secundarios y universitarios, pues históricamente han sido segmentos del movimiento estudiantil con discursos y demandas específicos, así como dinámicas organizativas y de acción también particulares, además de representar conjuntos etarios diferenciados (los secundarios tienen entre 12-18 años y los universitarios entre 19-25 años). Para los secundarios, el requisito era haber cursado $1^{\circ}$ o $2^{\circ}$ medio durante 2011; para los universitarios, $1^{\mathrm{er}}$ o $2^{\circ}$ año de su carrera durante 2011. En ambos casos la idea era que, al momento de los GD (año 2013), siguieran formando parte de sus respectivas esferas estudiantiles.

En tercer lugar, de ambos sexos, pues la participación política suele variar en alcance y naturaleza entre hombres y mujeres, e interesaba recoger eventuales diferencias.

Finalmente, pertenecientes a entornos que estructuralmente lideraron el movimiento. En el caso de los universitarios, se acotó la selección a las tres principales universidades CRUCH del país: Universidad de Chile, Universidad de Santiago de Chile y Ponti-

15 Detrás de la definición de cualquier criterio de selección existe también una intención por "dar voz" a unos sujetos determinados. En este caso, se optó por darla a aquellos que no la han tenido públicamente, es decir, a las bases activas cuyo discurso no ha sido plasmado por los medios de comunicación, a la vez que se corresponde con una mayoría de los movilizados. 
ficia Universidad Católica de Chile, con más énfasis en la primera de ellas, con mayor tradición y protagonismo contestatario. En cuanto a los secundarios, la selección consideró a los principales liceos emblemáticos, tanto masculinos - Instituto Nacional José Miguel Carrera, Liceo de Aplicación y Liceo José Victorino Lastarria- como femeninos — Liceo Carmela Carvajal, Liceo Javiera Carrera y Liceo 7-.

El material cualitativo generado a través de los GD fue analizado tomando como referencia el modelo del Análisis Sociológico del Sistema de Discursos (Conde, 2010), abordado mediante un proceso doble de codificación a partir de unas categorías preestablecidas (politización y subjetividad política; espacios de experiencia y aprendizaje biográfico; compromiso con el cambio social y activismo) y de levantamiento inductivo, generando categorías basadas en el corpus discursivo (quiebres y conflictos; tensiones y frustraciones). Para el análisis se utilizó el software Atlas-ti 6.2.

\section{Resultados}

\section{Posicionamientos discursivos de los actores}

Una primera aproximación al material obtenido apunta a situar a los actores en su marco social, de modo de establecer desde dónde hablan. Los actores hablan básicamente desde cinco posiciones. La primera, compartida por todos, es la de activista o miembro activo del movimiento estudiantil de 2011. La segunda, también compartida, hace referencia a su ubicación en la estructura socioeconómica, resultando que los grupos hablan desde una posición de clase media, con la heterogeneidad existente en ese grupo social, pero con ciertas características comunes que los sitúan en un espacio distinto al de la clase alta y al de la clase baja ${ }^{16}$. La tercera posición, distinta entre grupos, hace referencia

\begin{tabular}{l}
\hline La discusión académica relativa a la estratificación social ha sido muy prolífica \\
en el último tiempo, y en particular en Chile ha habido un interesante debate sobre
\end{tabular} 
a lo biográfico y ciclo vital: en promedio, 5 a 6 años de edad separan a secundarios de universitarios, con lo que ello implica en términos de experiencia biográfica y visión del mundo. Ligada a la anterior, la cuarta posición es la de estudiante secundario o universitario, correspondiente a ámbitos experienciales y formativos distintos. Finalmente, la quinta posición hace referencia al género, distinguiendo entre grupos masculinos y femeninos.

La definición analítica de estas cinco posiciones no implica que en el nivel de discurso existan diferencias significativas o sustantivas. De hecho, el análisis de los discursos da cuenta de grandes espacios de transversalidad y comunalidad, con ejes de contenido compartido que permiten nuclear el análisis. Escapan a este núcleo solo algunas visiones. Una de ellas es la que distingue entre universitarios y secundarios en relación a su aproximación a la política. Estos últimos conocieron la política y la experimentaron por primera vez en el liceo, en el marco de las movilizaciones, construyendo un valor en torno a la política directa y cotidiana, y un rechazo a la política formal y a la democracia representativa o delegada. En el caso de los universitarios, más bien hay un desencantamiento de la política institucional o una confirmación de sus falencias tras experiencias previas, ya sea como secundarios o participantes de colectivos.

Contrario a lo supuesto inicialmente, el género no constituyó un eje diferenciador de los discursos, salvo la apreciación mayoritaria, de parte de las propias estudiantes, de que las mujeres participaban y se involucraban menos que los hombres en las tomas.

el asunto. Recomendables son los trabajos de Emmanuelle Barozet (Barozet y Espinoza, 2009; Barozet y Fierro, 2011; Barozet y Mc-Clure, 2014). Para efectos del presente análisis, simplificamos la clasificación a partir de dos factores: i) Índice de vulnerabilidad escolar (IVE) del establecimiento educacional al que asisten (en el caso de los liceos); y ii) Comuna de residencia (en Santiago de Chile, la comuna y el nivel de ingresos están fuertemente correlacionados). 


\section{Tomas, politización y subjetividades}

La experiencia de las movilizaciones del año 2011 se constituye en un hito que marca un antes y un después en las vidas de los estudiantes que participaron en ellas. Ya se trate de individuos a los que pilló entrando en la adolescencia, con 15 años de edad o poco más, o de aquellos que las vivieron empezando o a punto de empezar la segunda década de sus vidas, su vivencia los ha marcado hondamente ${ }^{17}$.

Durante 2011 se registran tomas en al menos 466 liceos y 22 universidades (Fernández, 2013b), ya sea solo por unas horas o por meses (la casa central de la Universidad de Chile estuvo 195 días ocupada por los estudiantes). Los estudiantes ocupan los centros educativos, los cierran, paralizando las clases y manteniéndose en su interior día y noche, realizando tanto asambleas en las que se debate sobre las movilizaciones y sus demandas, como una serie de actividades libres: talleres, jornadas culturales, deportivas u otras. Tras los días de toma, variables en cada establecimiento, bien puede producirse el desalojo violento por parte de la policía o el abandono del recinto en forma voluntaria por decisión de la propia asamblea de estudiantes.

En la experiencia de la toma, diversos temas se ponen en cuestión; se debate, se aprende de otros, se opina y se construye alternativas, bajo la premisa de que todo orden de cosas está sujeto a transformación, no es eterno ni inmutable, sino que puede cambiar sobre la base de decisiones humanas, decisiones colectivas: decisiones políticas.

\section{Cita 1: Aprendizaje político}

A mí desde el 2011 en ese sentido me cambió la vida entera, porque me politicé el 2011, entonces, de no saber nada, a empezar a estudiar y a investigar lo que pasaba

\footnotetext{
17 Las jornadas de movilización se extendieron por alrededor de ocho meses. Algunos establecimientos permanecieron tomados casi durante todo ese tiempo.
} 
en el ámbito nacional, igual es como fuerte de un día para otro estar movilizado e informarte en todo ámbito, no solamente en el estudiantil.

El 2011 aprendimos que todo lo que habiamos aprendido durante 14 o 15 años se basaba prácticamente en puras mentiras, que todas las leyes y normas sociales eran cosas que no necesariamente tenían que ser así, o sea, el vivir siete meses dentro de una toma, en que no existía ninguna norma ni ninguna ley, más que las que poníamos nosotros mismos con nuestros compañeros, es una cuestión que enriqueció mucho, nosotros mismos desde la toma, más allá de lo que fue para afuera, sino que al interior de la toma, fue construir un mundo totalmente nuevo (...) todo lo que nos habían dicho desde que nacimos hasta esa época, eran básicamente mentiras y todo se podía cambiar. (Grupo de discusión de hombres secundarios, 2013)

En mi casa como que no se hablaba mucho de política, y cuando empezaron a salir los panfletos de 'vamos a la toma', 'informémonos' y el CODECU, yo ahí entendí lo que era la política, y hay como un antes y un después en mi vida, en mi pensamiento y también un antes y un después en mi casa, en mi familia en las horas de almuerzo y en las conversaciones, y lo veo como algo positivo, siento que para hacer un cambio necesitamos saber de política, necesitamos hablar de política. (Grupo de discusión de mujeres secundarias, 2013)

Hubo una apropiación de la política. Los estudiantes comprenden que la política la puede hacer cualquiera, de hecho, que la hacen todos; no es algo que pertenezca a los políticos y que se despliegue slo en el palacio de gobierno o en el Congreso Nacional. La política está en las acciones cotidianas y en la calle, pues corresponde a toda construcción colectiva y a todo intento de transformación, por pequeño que sea. En estos términos, la política es valorada, puesto que ellos mismos son actores políticos. 
Cita 2: Apropiación de la política

El 2011 dejé de creer que la política era para gente que ya estaba en eso, en el fondo, me permitió dar el salto para conocer gente, para participar, saber que se podía discutir cosas y que había maneras de hacer más grupales.

Siento que la política está en todo acto, cotidianamente, hoy en día cualquier cosa que hagai puede ser un acto político, andar en bici, o si estai en contra de las transnacionales, no consumir coca-cola, es un acto político (...) nos tomamos muy poco en serio a nosotros mismos como actores día a día en nuestra sociedad". (Grupo de discusión de hombres universitarios, 2013)

Pa mí, se revalidó la política, somos políticos, todo lo que hacemos es político y tenemos que entenderlo así.

Fue entender que la política no eran solamente los que estaban sentados en el Congreso o discutiendo en La Moneda, sino que la política la hacíamos nosotros mismos, en el momento en que decidiamos cómo se iba a repartir la comida o a qué hora hacer guardia, eso de por sí era un acto político y que iba construyendo comunidad, y cómo un acto simple como ese podía ayudar a cambiar las estructuras políticas de la sociedad. (Grupo de discusión de hombres secundarios, 2013)

Yo me di cuenta que la política la hacía cualquier persona, desde la crítica cotidiana (...) todos los seres humanos somos políticos y la política está en todo. (Grupo de discusión de mujeres secundarias, 2013)

De la mano de lo anterior, existe también un desencantamiento o desilusión de la política institucional y de los políticos, sentimiento que en otros casos corresponde más a una reafirmación de una opinión ya existente. La coexistencia de diversos colectivos políticos, incluyendo desde las tradicionales facciones de los partidos políticos formales hasta los grupos alternativos y de carácter libertario, y las relaciones con el poder institucional entre los dirigentes, grupos estudiantiles y actores externos, implicó darse 
cuenta de que la política que se despliega en la esfera formal es considerada sucia, pues quienes la ejercen terminan por estar envueltos en prácticas que no responden a la lealtad con las bases.

Hay un cuestionamiento severo de cómo funciona la política formal, caracterizada por una dinámica de luchas de interés en la que caen incluso los propios dirigentes estudiantiles una vez que son cooptados por los partidos políticos. En el fondo, se cuestiona a la democracia representativa, indirecta y delegada, y se valora en contraposición la política directa, cotidiana, en la que las acciones propias marcan el rumbo. La fuerza/poder se sitúa en los circuitos ciudadanos y no en el sistema político formal.

En ese marco, en la esfera de las tomas se experimentó la posibilidad de vivir un espacio de libertades y de construcción propia del orden, con reglas y acuerdos decididos de forma autónoma. Aparece la experiencia de la toma como un espacio de convivencia cotidiana que representa el constituir comunidad, el vivir con otros y tener conciencia de estar con el otro y trabajar juntos. A decir de algunos, la toma significó "educarse en la vida, más allá de los libros". En el día a día se aprende a compartir, a distribuirse tareas, también a discutir puntos de vista diferentes. Se aprende a convivir y a organizarse, realizando actividades definidas libremente.

En la práctica y en el debate diarios, se toma conciencia de lo que ocurre en el país, se sale del mundo limitado que representa la familia y el círculo cerrado de amistades, para conocer opiniones y realidades diferentes.

Cita 3: Otras realidades, otros aprendizajes

Asistir a las asambleas de noche, las asambleas para la seguridad de la toma, las asambleas para salir a marchar, las cosas domésticas como limpiar los baños, quien va a cocinar, la hora de dormir, entonces igual en ese sentido el 2011 también marcó un hito de salir un poco de mi burbuja de mi casa, de ir a la universidad, que aun así es una burbuja, pero estar en la toma es otro aprendizaje. (Grupo de discusión de mujeres universitarias, 2013) 
O sea, como que entrabai y cruzabai una puerta y estaban como en un lado compadres tocando música, con los instrumentos ahí, el que quería improvisaba... y en otro sector unos cabros enseñando, haciendo clases, enseñando circo a otros y en otro lado como secundarios aprendiendo como hacer matemáticas, en otra parte unos cabros jugando a la pelota y en una sala viendo documentales y en una sala escribiendo un proyecto de educación y fue como, por fin, en el fondo ahí como que le encontré mucho sentido al paro. (Grupo de discusión de hombres universitarios, 2013)

\section{Experiencia, aprendizaje y reflexión}

El periodo de tiempo que duraron las movilizaciones constituyó un espacio experiencial que ayudó a configurar de manera significativa la identidad de los activistas. Las relaciones establecidas con compañeros y personas que compartían intereses e inquietudes, un modo de ver la vida e incluso estilos de música determinados, generaron una unión y sentido de comunidad. Se creó un núcleo de amistades y relaciones, y una identidad personal y colectiva asociada a una postura crítica frente a la realidad social, especialmente en el ámbito educativo ${ }^{18}$.

Cita 4: La construcción de identidad

A mí el movimiento del 2011 me marcó mucho, me marcó mucho, tanto en cuestiones básicas de comportamiento como de en cuestiones, no sé, los temas que me interesan, la música que escucho, cuestiones así, como muy propias y que de ahí han derivado en cuestiones que, de no ser por el movimiento del 2011, nunca hubieran sido y que de alguna forma por supues-

\footnotetext{
18 También se tradujo, en algunos casos, en el desarrollo de habilidades sociales vinculadas con el relacionarse con distintos grupos. Esto es manifiesto en aquellos que, dentro de las movilizaciones, realizaban la labor de comunicación o difusión, que debían visitar distintos liceos para entregar información sobre lo que estaba ocurriendo en el conjunto de los establecimientos.
} 
to siguen asociadas. La gente con la que me junto, la forma con la que me relaciono con la gente también cambió.

Fue un periodo de enriquecimiento político y cultural muy, muy grande (...) como decía él, la forma en que veía a las otras personas, la música que escucho, todas esas cosas se vieron como muy influenciadas. (Grupo de discusión de hombres secundarios, 2013)

Para mí fue un momento de aprendizaje de cómo ver las cosas, cómo relacionarme con la gente, más que político, fue un cambio valórico total, maduré mucho. (Grupo de discusión de hombres secundarios, 2013)

[El 2011] en mi caso personal, y yo creo que, para todos, fue un antes y un después, las cosas que vivimos, las personas que conocimos, las realidades, me dieron nuevas enseñanzas y me hicieron otra persona. (Grupo de discusión de mujeres secundarias, 2013)

Por otro lado, las movilizaciones permitieron una reflexión —aunque emergente e inacabada- más allá de las demandas emblemáticas del movimiento, en relación con el tipo de educación deseada, con los fines de la educación en la sociedad. Si bien no se constituyó en el centro del debate (difícil que lo fuera, cuando antes había que resistir la mercantilización extrema de un derecho), surgió como inquietud y como foco de diálogo entre los estudiantes a partir de las propias jornadas de movilización. La experiencia de la toma abrió la puerta a pensar en una educación que incluyera diversos aspectos más allá de los que incorpora el actual currículo, a pensar en una educación para ejercer la ciudadanía más que para la inserción laboral, e incluso en una educación administrada comunitariamente, desligada de la intervención del mercado y del Estado.

Cita 5: Debates pendientes en educación

Nosotros no estamos discutiendo qué educación queremos, y esa es la cuestión más fundamental creo yo porque finalmente 
lo que, la disputa debería ser así, o sea nosotros queremos un modelo educativo completamente distinto. Quizás, como dicen los secundarios, por ejemplo, los secundarios dicen: 'nosotros queremos control comunitario de la educación', que es como completamente distinto a lo que tiene este modelo, pero en realidad esa crítica no se pudo instalar po. O sea, nosotros no le pudimos decir a la gente: 'no, en realidad yo quiero educación gratuita, pero en realidad no quiero educación para la explotación, cachai? (Grupo de discusión de hombres universitarios, 2013)

La educación social, hoy la educación está para lograr algo, no para desarrollarte tú como individuo (...) falta para poder verla como un sistema de adquisición de conocimientos y no como una imposición donde solo el profesor sabe, el profesor también obtiene conocimiento y el alumno también (...) hay que cambiar toda la estructura de qué se enseña, de cómo se enseña, cómo queremos enseñar, qué es lo que queremos como proyecto país y qué queremos mostrar a la ciudadanía. (Grupo de discusión de hombres secundarios, 2013)

\section{Quiebres y la experiencia de la comunidad fragmentada}

Las tomas tuvieron un significado ambivalente en cuanto a las relaciones sociales, a uniones y divisiones. Fueron espacios de construcción de identidad y de alma colectiva. Sin embargo, también fueron escenario o causa de profundas divisiones.

Primero, divisiones entre compañeros. El primer quiebre se produjo entre quienes apoyaban las marchas y las tomas, y quienes no lo hacían. Luego, y de manera más notoria, entre quienes participaban activamente de las mismas y quienes no se involucraban en ellas. Para quienes participaron, fue un aprendizaje indeseable, por cierto- el darse cuenta de que había compañeros que, pese a compartir su misma realidad social y educativa, se 
mostraban indiferentes, indolentes frente a lo que ocurría, desinteresados respecto de las movilizaciones. Tras esa experiencia era muy difícil poder volver a tener cercanía con aquellos que se quedaban en sus casas o se tomaban "unas largas vacaciones", mientras ellos pasaban hambre, frío, represión policial (lo negativo), a la vez que aprendían, debatían, reflexionaban y se construían como ciudadanos (lo positivo).

Tras el fin de las tomas y el retorno a clases, la situación tuvo un nuevo cariz. Volver a clases era volver a aquello contra lo que se había luchado durante un año, era la rutina y el modelo educativo, esta vez con una presión adicional por la necesidad de recuperar el "tiempo perdido". Además, el reencuentro con los compañeros que no participaron de las movilizaciones también significó una desilusión. Más allá de las divisiones que pudieran haberse producido entre amigos, la presencia de aquellos que retornaban con "ganas de volver a estudiar" después de haber estado en sus casas era chocante para quienes habían comprometido esos meses en el esfuerzo de luchar para cambiar las cosas. Era decepcionante que campeara la indolencia y la falta de compromiso, lo cual tendía a generar menor optimismo frente al futuro de los cambios.

Cita 6: Quiebres y conflictos

Lo más penca del 2011 fue el quiebre de las comunidades dentro de los liceos, como después, cuando llegamos en marzo del otro el año, nos dimos cuenta que estaba más de la mitad del liceo que durante 7 u 8 meses no habían hecho nada, que no habían vivido ningún proceso de maduración y habian estado como vegetando en su casa, que no sabian de nada, y ahí uno se da cuenta que el compañero de tu misma sala de clases no cacha nada, que incluso fue un proceso que los convirtió en más niños chicos (...) el 2012 yo creo que fue lo más difícil, volver a unir las rupturas. (Grupo de discusión de hombres secundarios, 2013) 
Después del 2011 eran los que repitieron y los que no, y eso quebró relaciones, había gente que no se podía ver a la cara. (Grupo de discusión de mujeres secundarias, 2013)

$\mathrm{Al}$ interior del movimiento se evidenciaron dos rupturas adicionales, especialmente dentro de los secundarios. Una entre los activistas de base y los dirigentes. La percepción era que, mientras los activistas de base apoyaban las movilizaciones cotidianamente y hacían funcionar la toma en el día a día, los dirigentes se reunían a nivel de cúpulas y sus negociaciones con los políticos les hacían distanciarse del sentir de los estudiantes movilizados. La impresión de que finalmente se "vendían" por dinero o por un celular (secundarios), o por asegurar un futuro cargo en la institucionalidad (universitarios), operaba una ruptura con los líderes y un cuestionamiento a su capacidad para representar válidamente los intereses del movimiento social.

Cita 7: Activistas de base vs dirigentes

Nosotros éramos los que trapeábamos todos los días, los que limpiábamos los baños, que teníamos que hacer la comida, y los centros de alumnos se quedaban en reuniones, por allá y por acá, y nosotros éramos los que estábamos haciendo que la cosa funcionara, no los centros de alumnos, y en un momento hubo una bifurcación entre quienes estuvieron resistiendo y luchando con la toma y los centros de alumnos que no hacían mucho, y quienes terminaron teniendo la participación política en la toma fueron los que se quedaban, los que estaban ahí, no los centros de alumnos (...) en muchos liceos fue así, los que se quedaban tomaban la iniciativa y los centros de alumnos se fueron como más de lado (...) nosotros tuvimos una experiencia particular, que hubo jóvenes que estuvimos consiguiendo dinero para que participaran en una marcha al Congreso en Valparaíso y allá algunos centros de alumnos estaban en una reunión en el Congreso, comiendo con parlamentarios, y otros que no tenían cómo llegar, nació como una desconfianza en ese sentido. (Grupo de discusión de hombres secundarios, 2013) 
La segunda ruptura, que cambia con el tiempo, opera entre quienes legitiman la violencia como medio de acción y los que la rechazan. Es interesante que, al principio, el repudio a los actos de violencia y el rechazo a los capucha ${ }^{19}$ era mayoritario; sin embargo, con el paso del tiempo y los eventos en torno a las movilizaciones, se fue matizando la crítica y las acciones violentas pasaron a tener legitimidad para muchos estudiantes.

Cita 8: Legitimación de la violencia

En mi carrera hubo un momento que se radicalizó mucho el lenguaje, también en la asamblea, como habían compañeros míos que decían 'bueno aqui están los que están a favor y los que están en contra', así como parte de la solución parte del problema, entonces chuta, era como (...) mucha gente que estaba a favor de la demanda pero no a favor del método que estaba usando y era súper legitimo, se llegó a unos niveles de violencia muy altos. (Grupo de discusión de mujeres universitaria, 2013).

Nos dimos cuenta que la protesta, así super colorida, no servía de nada, y lo único que quedaba era descargarse, y la descarga era con la capucha, con el piedrazo, era la alternativa que quedaba.

Yo me acuerdo que cuando empezaron las marchas y aparecieron los primeros encapuchados, todos los pifiábamos, los agarraban a combos, pero con el pasar del tiempo todos terminaron siendo capuchas, hasta el más hippie.

Yo al inicio de las marchas criticaba a los encapuchados, oye cómo hacen esto, estamos aquí con la ciudadanía, pero pasado un tiempo, a los 4 meses, yo me quebré, una vez me llevaron detenido, pasé por Fiscalía y no había hecho nada, era pacifista

\footnotetext{
19 Se denomina "capucha" a quienes participan en las movilizaciones provocando destrozos en el mobiliario público o privado, levantan barricadas en la calle y se enfrentan con la policía. Para ocultar su rostro andan "encapuchados", de ahí su nombre.
} 
y me llevaron y sufrí todo el proceso por estar en contra de los encapuchados, entonces pasó un quiebre, dije, llevamos 4 meses gritando, 4 meses en las calles, ya por la vía pacífica esto no se puede resolver". (Grupo de discusión de hombres secundarios, 2013)

\section{Declive, agotamiento de la toma, frustración y proyección a futuro}

El paso del tiempo y el desgaste natural de un proceso contestatario intenso, fue debilitando las energías y también, en alguna medida, las ilusiones de los estudiantes que veían que lo habían intentado todo - marchas, paros, tomas, performances, flashmobs-, durante todo el año, con gran masividad y respaldo ciudadano, y pese a todo las autoridades del gobierno no cedían, no recogían las principales demandas del movimiento y mantenían el modelo educativo incólume. Asimismo, a la primera etapa "alegre" seguiría una marcada por el aumento de la violencia, con agentes infiltrados en las marchas, desalojo de establecimientos, abusos policiales contra menores de edad, aumento de enfrentamientos en barricadas y desmanes en espacios públicos.

El desgaste tuvo también motivos internos. Baja participación en las asambleas y en las tomas, cansancio y frustración. A medida que avanzaba el año, la asistencia a las asambleas y tomas bajó progresivamente, ya sea porque la dinámica del debate se hizo muy dura (ataques verbales, discusiones no dialogantes) o porque sus temas pasaron en algunos casos a privilegiar la situación interna de las tomas por sobre la externa del movimiento nacional (esto especialmente en los secundarios).

Cita 9: La toma como fin en sí misma

Tanto la toma, la toma, la toma, se olvidaron de que la toma no era un fin, era un medio para llegar a algo más, era un medio para ejercer presión, era un medio para organizarse, era un medio para sacar marchas y hacer lienzos, hubo un momento 
en que la toma se encerró tanto en la toma, que todo el apoyo social que se ganó desde junio hasta septiembre, todo el poder que se tuvo en las manos, como que se escapó de las manos, cómo nos organizamos, cómo nos organizamos, y estamos aquí, y la gente está afuera, y nosotros haciendo un experimento social dentro del liceo.

Cuando comenzó la decadencia del movimiento a nivel de secundarios, fue cuando la toma se empezó a centrar en la toma misma, cuando uno hacía una asamblea y en vez de tratar temas políticos, se trataban temas de convivencia, en ese momento yo decía esto se está pudriendo (...) encontraba super estúpido que teniendo lo que teníamos afuera, empezáramos a quebrantarnos por temas de convivencia. (Grupo de discusión de hombres secundarios, 2013)

La frustración condujo a dos escenarios que oscilan en el discurso de los estudiantes, pero que se decanta por el segundo. El primero muestra decepción y la idea de una renaturalización del orden social: "no ganamos nada y quedamos donde mismo, los únicos que perdimos fuimos nosotros, plata, vacaciones, ramos..." (mujeres universitarias); "políticamente no se hizo nada concreto" (hombres secundarios).

No obstante, el más fuerte es el segundo discurso, que refleja que los activistas internalizaron una actitud orientada a la transformación y a la lucha legítima en la defensa de sus derechos. De manera transversal, señalan que continuarán en su vida con la intención de lograr cambios sociales, desde los distintos campos en los que les toque estar, ya sea como trabajadores en sindicatos, o desempeñándose en actividades como la docencia o profesiones del área social. La proyección política de los activistas se manifiesta en una vocación por el cambio social.

Cita 10: Activismo proyectado al futuro

Hay que luchar constantemente, si luché como secundaria, después como universitaria y después como trabajadora, por 
un cambio también para la situación de mis hijos, no sé si tenga, pero creo que hay que luchar constantemente, el derecho a huelga, no podemos decir me movilicé como estudiante y luego se acabó y sigo con mi vida, nos estaríamos resignando a lo que quieren imponernos, y vamos comprando y saca una tarjeta y cómprate un celular... (Grupo de discusión de mujeres secundarias, 2013)

La verdad es que nosotros no nos vamos a ir de la realidad nacional, no nos vamos a ir a jubilar a otro país, sino que vamos a estar en el mismo país, en las mismas circunstancias, pero un poco más grandes y en otros contextos (...) yo siento que en la universidad - yo quiero estudiar Historia y sacar la pedagogía- (...) mi proyección frente a lo que he vivido y lo que quiero vivir es seguir siendo un actor, desde mi pequeño grano de arena, seguir aportando a la construcción de una sociedad que es la que nosotros queremos, más que la que nos están imponiendo, desde una juventud a la que le enseñen a pensar.

Cómo desde todas nuestras habilidades podemos ser personas activas social y políticamente, cómo podemos construir (...) si yo tengo una conciencia social, desde lo que hago puedo aportar.

Tenemos que mantener unas concepciones coherentes, en el mundo profesional, con lo que hemos vivido. (Grupo de discusión de hombres secundarios, 2013)

\section{Discusión y conclusiones}

A la luz de los discursos de los activistas, que dan cuenta del significado que le otorgan a las movilizaciones y en particular a su experiencia concreta en la toma, se observa la apropiación de la política, su resignificación como aquello que alude a toda decisión colectiva que afecta a uno o más grupos, con lo que está en todos los ámbitos de la vida social y puede ser ejercida por todos y cada uno de los actores sociales. Existe politización, y esto es significativo, por cuanto se pone al sistema educativo 
y al marco social más amplio en el plano de lo colectivamente modificable.

Al proceso de politización contribuyen las tomas, constituidas en "espacios libres", de autonomía y aprendizaje, de cuestionamiento del orden cotidiano y de puesta en práctica de reglas y funciones autodefinidas colectivamente. La constitución de actores políticos se evidencia en ese proceso, en el que, desde las funciones de cada uno en el día a día, hasta la toma de decisiones que trascienden el espacio del establecimiento educacional, se experimenta la unidad, el conflicto y la posibilidad de construcción del orden, representando para los estudiantes una experiencia de constitución de actores en lo cotidiano.

Más de la mitad de los activistas participantes de los grupos de discusión declaran no haber participado antes del 2011 en colectivos políticos ni en actos de protesta asociados a alguna causa, fuera o no estudiantil. Ello es relevante y permite ir más allá de la comprensión de la participación política como resultado de una determinada socialización previa en la familia, el grupo de pares o la escuela, para enfocarse en el proceso de aprendizaje y construcción política durante las jornadas de movilización.

Específicamente, la toma, como espacio de experiencia y aprendizaje se demuestra como crisol de actores políticos, como ámbito de reflexión y práctica política. En una esfera de autonomía, son los propios activistas los que definen los códigos regulatorios de su convivencia, sus obligaciones y libertades, su propósito como colectivo y los mecanismos dirigidos a su logro. Es escenario de comunión de intereses, de amistad y de colaboración, pero también de conflictos, de divisiones, quiebres y sacrificios.

La politización ocurre en una trama de dos niveles. En el nivel macro, ocurre un estallido social nacional en que los protagonistas son los estudiantes, los medios de comunicación amplifican el despliegue contestatario y se respira un aire de transformación, en el que la adhesión ciudadana mayoritaria y transversal dibuja 
un escenario en el cual se cree que es posible debatir acerca del orden social y definir colectivamente la forma que éste debe tomar. En ese proceso, los estudiantes no se sienten ajenos, sino, por el contrario, actores clave que han impulsado un movimiento que fue creciendo y haciendo sentido a la mayoría de la sociedad, poniendo temas que no estaban en la conversación social y enfrentando realidades que por mucho tiempo no se habían enfrentado de manera directa.

En el nivel micro, los estudiantes en la toma han experimentado el diálogo, la crítica, la anulación de las reglas previas y la generación de un nuevo orden al interior de sus establecimientos. Han conocido la experiencia de la disolución o reemplazo temporal de los centros de alumnos (modelo organizativo formal) para la configuración de asambleas en las que se debate y se toman decisiones. Han aprendido que en forma colectiva se puede organizar la cotidianeidad (quiénes limpian, quiénes cocinan, quiénes hacen talleres, quiénes se comunican con otros liceos, quienes cuidan el recinto, cuándo lo hacen y por qué), a la vez que las formas de expresión para plantear las demandas que la trascienden.

Se ha perdido el miedo al debate y al reclamo, al cuestionamiento y a la disconformidad, al tiempo que se ha aprendido a proponer y a trabajar por la construcción de una realidad diferente. No obstante, esa apropiación de la política se sitúa esencialmente extramuros del sistema político institucional. La desconfianza y la desilusión llevan a una búsqueda no institucional, a una comprensión de la acción política más allá de la participación electoral y más acá de los espacios cotidianos. Se internaliza que la realidad no es inmutable, pero también que las instituciones ayudan más a la conservación que a los cambios.

Lo anterior tiene implicancias, por cuanto la conformación y reproducción de una comunidad política nacional sigue siendo rol de las instituciones estatales (Lechner, 2002; Garretón, 2014), y en el momento en que se renuncia a participar de ellas - por válidos 
que sean los argumentos para hacerlo— de algún modo se renuncia también a estructurar la convivencia social y la construcción de un futuro común para todos, más allá de los espacios locales.

Junto con la politización, los activistas en la base del movimiento experimentan la participación en las jornadas de protesta como un hito vital (siendo adolescentes/jóvenes), situándolos en una relación crítica con distintos planos de la vida social (familia, compañeros de curso, políticos, autoridad, futuro). La realidad no es aceptada simplemente como es, sino que una realidad diferente se plantea como posibilidad, aunque el intento de llegar a concretarla implique quiebres, frustraciones, inseguridades y miedos.

La internalización de una visión crítica frente a la realidad y la comprensión de sí mismos como actores relevantes para que los cambios puedan tener lugar, representa un aprendizaje que cimenta una base de acción futura y una conciencia propiamente política.

La politización de los sujetos y su constitución como actores es probable que no opere sólo en tanto actor-estudiante, es decir, si bien ocurre en esa coyuntura, el actor que se configura no es el de estudiante — categoría por definición transitoria—, sino más bien es esperable que trascienda la condición estudiantil para ser parte de la construcción a largo plazo de la subjetividad política de los individuos (McAdam, 1999; Giugni, 2004, 2008). En el presente trabajo esto no puede verificarse y sólo es delineado como hipótesis en términos de proyección, abriendo una ventana a una futura investigación que aborde a los mismos sujetos una vez hayan dejado su posición de estudiantes y recorran una trayectoria en otros estadios de su ciclo vital y en otros campos de la vida social.

\section{Referencias}

Alonso, L. (1998). La mirada hermenéutica. Introducción a La Mirada Cualitativa en Ciencias Sociales. Madrid: Fundamentos.

Alvarado, S., Ospina, H., Botero, P. y Muñoz, G. (2008). Las tramas de 
la subjetividad política y los desafíos a la formación ciudadana en jóvenes. Revista Argentina de Sociología, 6(11), 19-43. Recuperado de http//www.scielo.org.ar/pdf/ras/v6n11/ v6n11a03.pdf

Barozet E. y Espinoza V. (2009). ¿De qué hablamos cuando decimos "clase media"? Perspectivas sobre el caso chileno. Universidad Alberto Hurtado-UDP-Expansiva, 142, 1-35.

Barozet, E. y Fierro, J. (2011). Clase media en Chile, 1990-2011: algunas implicancias sociales y políticas. Serie Estudios, (4), Konrad Adenauer Stiftung.

Barozet, E., Mac-Clure, Ó., y Maturana, V. (2014). Desigualdad, clase media y territorio en Chile: ¿Clase media global o múltiples mesocracias según territorios? Revista EURE, 40, 163-183. DOI: https://doi.org/10.4067/s0250-71612014000300008

Beck, U. (2002). La sociedad del riesgo global. Barcelona: Siglo XXI.

Conde, F. (2010). Análisis sociológico del sistema de discursos. Madrid: Cuadernos Metodológicos del CIS N 43.

Crouch, C. (2004). Posdemocracia. México D.F.: Taurus.

Crouch, C. (2011). The Strange Non Death of Neoliberalism. Cambridge: Polity Press.

Della Porta, D. (2012). Desperately Seeking Politics: Protesting for Social Justice in Italy. Seminario de la Facultad de Ciencias . Políticas y Sociología, Universidad Complutense de Madrid. 22 de marzo.

Fernández, J. (2013a). Movimiento estudiantil en Chile (2011): repertorios de acción, marcos de acción colectiva, impactos y desafíos para la política pública. Revista Circunstancia, XI(31). Recuperado de http://movimientoestudiantil.cl/ wp-content/uploads/2015/12/11-Movimiento-estudiantil-en-Chile-2011-Repretorios-de-accion-marcos-de-accioncolectiva-impactos-y-desafios-para-la-politica-publica.pdf

Fernández, J. (2013b). La Protesta social en Chile (2006-2011): conflicto social y repertorios de acción en torno a los movimientos estudiantil, mapuche y ambiental. GIGAPP Estudios/Working Papers. Instituto Universitario de Investigación Ortega y Gasset. Madrid, WP, 27(26). Recuperado de http://www. gigapp.org/administrator/components/com_jresearch/ files/publications/WP-2013-27.pdf 
Funes, M. J. (2003). Socialización política y participación ciudadana. Jóvenes en dictadura y jóvenes en democracia. Revista de Estudios de Juventud (Edición especial 25 aniversario Constitución). Madrid: INJUVE.

Funes, M. J. (2012). 2011: la política no convencional ¡a escena! En S. Aguilar (Ed.), Anuario del Conflicto Social 2011 (pp. 405428). Barcelona: Universidad De Barcelona. Recuperado de http: / / www.ub.edu/economiaempresa/butlleti/publicacio/wp-content/uploads/2013/06/anuari_2012_17_de_ mayo.pdf

Garcés, M. (2012). El despertar de la sociedad. Los movimientos sociales de América Latina y Chile. Santiago de Chile: LOM.

Garretón, M. A. (2011). Movilizaciones y movimiento social en la democratización política chilena. En La sociedad española en la Transición. Los movimientos sociales en el proceso democratizador. Madrid: Biblioteca Nueva. Recuperado de http:/ / www.manuelantoniogarreton.cl/documentos/2011/mag2011esp.pdf

Garretón, M. A. (2014) Las ciencias sociales y la trama de Chile y América Latina. Estudios sobre transformaciones sociopoliticas y movimiento social. Santiago de Chile: LOM.

Giugni, M. (2004). Personal and Biographical Consequences. En D. Snow, S. Soule y H. Kriesi (Eds.), The Blackwell Companion to Social Movements (pp. 489-507). Blackwell Publishing. DOI: https:/ /doi.org/10.1002/9780470999103.ch21

Giugni, M. (2008) Political, biographical, and cultural consequences of social movements. Sociology Compass, 2(5), 1582-1600. DOI: https:/ / doi.org/10.1111/j.1751-9020.2008.00152.x

Greenberg, E. (2017). Political socialization. Londres: Routledge. DOI: https: / / doi.org/10.4324/9781315126753

Gutiérrez, J. (2008). Dinámica del Grupo de Discusión. Madrid: Cuadernos metodológicos del CIS, $\mathrm{N}^{\circ} 41$.

Held, D. (1997). La democracia y el orden global: Del Estado moderno al gobierno cosmopolita. Barcelona: Paidós.

Ibañez, J. (1989). Perspectivas en la investigación social: el diseño en la perspectiva estructural. En F. Alvira, J. Ibáñez y M. García Ferrando (Eds.), El análisis de la realidad social. Métodos y técnicas de investigación (pp. 49-83). Madrid: Alianza Universidad. 
Lechner, N. (1999). Las condiciones sociopolíticas de la ciudadanía. Conferencia de clausura del IX Curso Interamericano de Elecciones y Democracia. Instituto Interamericano de Derechos Humanos-CAPEL e Instituto Federal Electoral, México D.F., 17-21 de noviembre.

Lobos, M. (2014). La influencia de las organizaciones políticas universitarias en la formación de élites políticas en Chile: el caso de las federaciones de estudiantes de la Universidad de Chile y Universidad Católica 1984-2005. Revista de Ciencia Política, 52(2), 157-183. DOI: 10.5354/0716-1077.2015.36140

López, R. y Figueroa, E. (2012). Cómo hacer que los ricos paguen más impuestos y la señora Juanita mucho menos. CIPER, (11), enero. Recuperado de http://ciperchile.cl/2012/01/11/ como-hacer-que-los-ricos-paguen-mas-impuestos-y-la-senora-juanita-mucho-menos /

Martín Criado, E. (1991). Del sentido como producción: elementos para un análisis sociológico del discurso. En M. Latiesa (Ed.), Pluralismo metodológico en en la investigación social. Granada: Universidad de Granada.

Martín Criado, E. (1997). El Grupo de discusión como situación social. REIS, 79(97), 81-112. DOI: http://dx.doi. org/10.2307/40184009

Mayol, A. (2012). El derrumbe del modelo. La crisis de la economía de mercado en el Chile contemporáneo. Santiago de Chile: LOM.

McAdam, D. (1999). The Biographical Impact of Activism. En M. Giugni, D. McAdam y Ch. Tilly, How Social Movements Matter (pp.119-148). Social Movements, Protest, and Contention, volume 10. University of Minessota Press.

Mönckeberg, O. (2007). El negocio de las universidades en Chile. Santiago de Chile: Random House Mondadori.

Mouffe, Ch. (2007). En torno a lo politico. Buenos Aires: Fondo de Cultura Económica.

Moulian, T. (1997). Chile actual. Anatomía de un Mito. Santiago de Chile: LOM.

Muñoz, V. (2011). Juventud y política en Chile. Hacia un enfoque generacional. Ultima Década, (35), 113-141. DOI: https:/ / doi. org/10.4067/s0718-22362011000200006

OCDE. (2012). Chile at a glance. OCDE. 
Patiño, J., Alvarado, S. V. y Ospina-Alvarado, M. C. (2014). Ampliación de sentidos sobre las prácticas políticas de jóvenes con vinculación a siete movimientos sociales en Colombia. Revista Latinoamericana de Ciencias Sociales, Niñez y Juventud, 12(1), 257-275. DOI: https://doi.org/10.11600/169271 5x.12115101012

Pleyers, G. (2010). Alter-globalization. Becoming actors in a global age. Londres: Polity Press.

PNUD. (1998). Las paradojas de la modernización. Informe Desarrollo Humano en Chile. Recuperado de http://desarrollohumano.cl/ idh/download/1998.pdf

Poletta, F. (1999). "Free Spaces" in Collective Action. Theory and Society, 28(1),1-38. DOI: https:/ / doi.org/10.1023/A:1006941408302

Poletta, F \& Kretschmer, K. (2013). Free spaces. En D. A. Snow, D. della Porta, B. Klandermans, y D. McAdam (Eds.), The Wiley-Blackwell Encyclopedia of Social and Political Movements. Blackwell Publishing Ltd. DOI: 10.1002/9781405198431. wbespm094

Ponce, C. (2013). La socialización política en el aula: comparación entre las movilizaciones de Francia y Chile. Revista Latinoamericana de Ciencias Sociales, Niñez y Juventud, 11(2), 603-615. DOI: https:/ / doi.org/10.11600/1692715x.11210210113

Ponce, C. (2016). Claves para entender a los líderes universitarios chilenos y a sus organizaciones políticas. En M. Jiménez (Coord.), Jóvenes en movimiento en el mundo globalizado (pp. 405-435). México D.F.: Editorial UNAM.

Quintelier, E. (2013). Engaging Adolescents in Politics: The Longitudinal Effect of Political Socialization Agents. Youth \& Society, 47(1), 51-69. DOI: https:/ / doi.org/10.1177/0044118x13507295

Resnick, P. (2007). La democracia del siglo XXI. Barcelona: Anthropos.

Sandoval, J. y Hatibovic, F. (2010). Socialización política y juventud: el caso de las trayectorias ciudadanas de los estudiantes universitarios de la región de Valparaíso. Última Década, 18(32), 11-36. DOI: https://doi.org/10.4067/s071822362010000100002

Treviño, E., Villalobos, C., Béjares, C. y Naranjo, E. (2018). Forms of youth political participation and educational system: the role of the school for 8th grade students in Chile. Young, 27 (3), 279-303. DOI: https:/ / doi.org/10.1177/1103308818787691 
UDP (2012). Encuesta Nacional Chile 2012. ICSO. Recuperado de http:/ / encuesta.udp.cl/

Valles, M. (1997). Técnicas cualitativas de investigación social. Reflexión metodológica y práctica profesional. Madrid: Síntesis.

Valles, M. (2002). Entrevistas cualitativas. Madrid: Cuadernos Metodológicos del CIS $\mathrm{N}^{\circ} 32$. 


\section{ANEXOS}

\section{Características de los grupos}

Tabla 1

Distribución del número de grupos según sexo y centro educativo y total de participantes $^{20}$

\begin{tabular}{|l|c|c|c|}
\hline Sexo & Secundarios & Universitarios & Total participantes \\
\hline Masculino & 2 & 2 & 26 \\
\hline Femenino & 2 & 2 & 16 \\
\hline Total participantes & 17 & 25 & 42 \\
\hline
\end{tabular}

*Los Grupos de Discusión (GD) se realizaron entre el 22 de agosto y el 17 de diciembre de 2013. En los Grupos participaron un mínimo de 4 y un máximo de 8 activistas, siendo los grupos femeninos los que tuvieron menor número de participantes.

El proceso de selección fue a través de redes de contactos y efecto "bola de nieve", respetando que se cumplieran los criterios establecidos. Si bien es probable que se haya dado una autoselección entre el universo de contactados, participando los más "proactivos", se cumplió el objetivo de que no fueran dirigentes.

Junto con la participación de los activistas en los Grupos de Discusión, cada uno de ellos rellenó una ficha de caracterización. Adicionalmente, se recolectó información acerca de sus establecimientos educativos, con el objeto de situarlos en su contexto y así comprender a cabalidad "desde dónde" están hablando.

\footnotetext{
20 Resultó muy difícil convocar exitosamente a estudiantes secundarias. Se hizo esfuerzos muy superiores respecto de los varones (invitaciones reiteradas y modificación de fechas de reunión), sin embargo, la asistencia fue baja. Las razones esgrimidas por ellas iban desde "no querer hablar de nuevo del tema", hasta "tener que preparar la PSU y no tener tiempo".
} 
Tabla 2

Caracterización de los activistas estudiantes universitarios

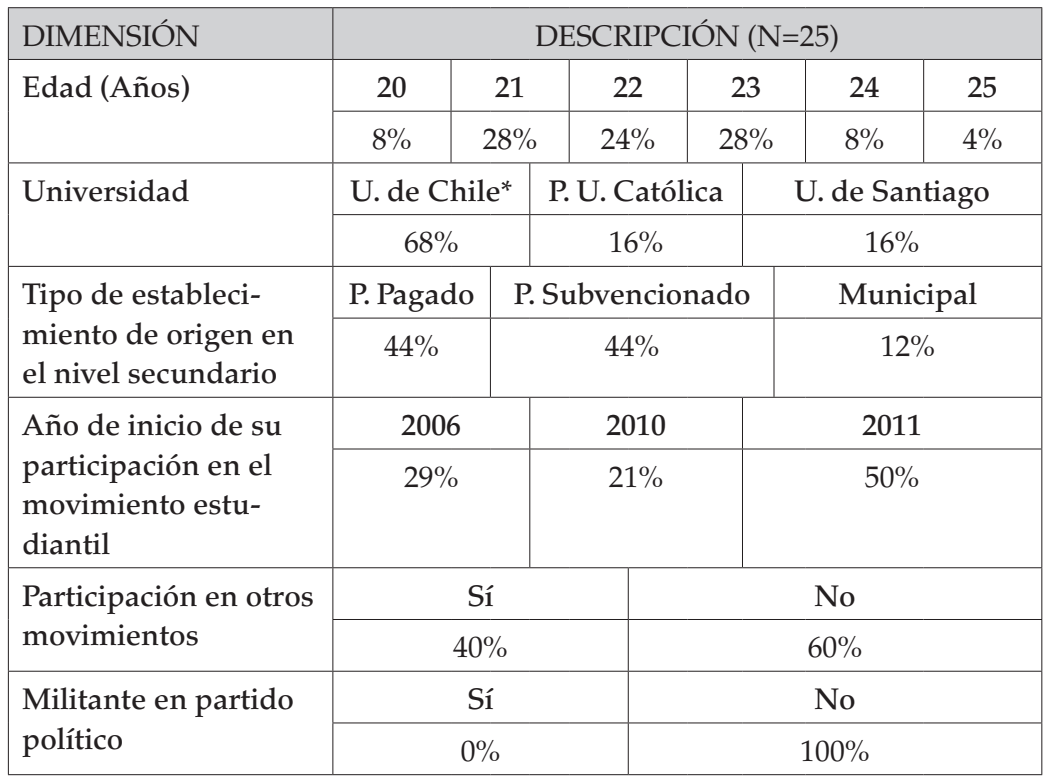

* La Universidad de Chile históricamente ha jugado un rol protagónico en las luchas estudiantiles, presidiendo la CONFECH y exhibiendo una significativa capacidad de movilización de sus estudiantes, por ello su número y \%.

En cuanto a las carreras de los participantes, estas son: $32 \%$ ingeniería civil (distintas menciones); 20\% periodismo; 16\% sociología; $8 \%$ psicología; $8 \%$ pedagogía en inglés; $4 \%$ ciencia política; $4 \%$ cine y tv; $4 \%$ veterinaria; y $4 \%$ letras hispánicas.

Destaca que la mitad de los activistas haya comenzado su activismo precisamente en 2011, así como que ninguno de los participantes milite en algún partido político. Quienes participan en otros movimientos, lo hacen en organizaciones ambientalistas, colectivos libertarios y entidades de voluntariado. 
Tabla 3

Caracterización de los activistas estudiantes secundarios

\begin{tabular}{|c|c|c|c|c|}
\hline DIMENSIÓN & \multicolumn{4}{|c|}{ DESCRIPCIÓN (N=17) } \\
\hline \multirow[t]{2}{*}{ Edad (Años) } & 17 & 18 & \multicolumn{2}{|c|}{19} \\
\hline & $18 \%$ & $58 \%$ & \multicolumn{2}{|c|}{$24 \%$} \\
\hline \multirow[t]{2}{*}{ Liceo (hombres) } & $\begin{array}{l}\text { I. Nacio- } \\
\text { nal }\end{array}$ & L. de Aplicación & \multicolumn{2}{|c|}{ J.V. Lastarria } \\
\hline & $31 \%$ & $38 \%$ & \multicolumn{2}{|c|}{$31 \%$} \\
\hline \multirow[t]{2}{*}{ Liceo (mujeres) } & $\begin{array}{c}\text { L. C. } \\
\text { Carvajal }\end{array}$ & \multicolumn{3}{|c|}{ L. J. Carrera } \\
\hline & $50 \%$ & \multicolumn{3}{|c|}{$50 \%$} \\
\hline \multirow[t]{2}{*}{ Curso actual } & \multicolumn{4}{|c|}{$4^{\circ}$ E. Media } \\
\hline & \multicolumn{4}{|c|}{$100 \%$} \\
\hline \multirow{2}{*}{$\begin{array}{l}\text { Año de inicio de su } \\
\text { participación en el mo- } \\
\text { vimiento estudiantil }\end{array}$} & 2008 & 2009 & 2010 & 2011 \\
\hline & $18 \%$ & $12 \%$ & $18 \%$ & $53 \%$ \\
\hline \multirow{2}{*}{$\begin{array}{l}\text { Participación en otros } \\
\text { movimientos }\end{array}$} & \multicolumn{2}{|r|}{ Sí } & \multicolumn{2}{|c|}{ No } \\
\hline & \multicolumn{2}{|r|}{$29 \%$} & \multicolumn{2}{|c|}{$71 \%$} \\
\hline \multirow{2}{*}{$\begin{array}{l}\text { Militante en partido } \\
\text { político }\end{array}$} & \multicolumn{2}{|r|}{ Sí } & \multicolumn{2}{|c|}{ No } \\
\hline & \multicolumn{2}{|r|}{$12 \%$} & \multicolumn{2}{|c|}{$82 \%$} \\
\hline
\end{tabular}

Destaca, al igual que en el caso de los universitarios, que más de la mitad de los activistas haya comenzado su activismo precisamente en 2011. Por otro lado, a diferencia de aquéllos, algunos sí participan en algún partido político (juventudes comunistas y juventudes socialistas). Quienes participan en otros movimientos lo hacen en colectivos libertarios, organizaciones en la temática de derechos humanos y preuniversitario popular (hombres) y en organizaciones ambientalistas (mujeres). 